\title{
The Effects of Cognitive and Visual Functions of Korean Elderly Taxi Drivers on Safe Driving Behavior
}

This article was published in the following Dove Press journal:

Risk Management and Healthcare Policy

\author{
YeongAe Yang ${ }^{1,2}$ \\ Hyejin Lee $\mathbb{D}^{3,4}$
}

'Department of Occupational Therapy, College of Biomedical Sciences and Engineering, Inje University, Gimhae, Republic of Korea; ${ }^{2}$ Institute of Aged Life Redesign, Inje University, Gimhae, Republic of Korea; ${ }^{3}$ Department of Occupational Therapy, Choonhae College of Health Sciences, Ulsan, Republic of Korea; ${ }^{4}$ Department of Rehabilitation Science, Graduate School of Inje University, Gimhae, Republic of Korea

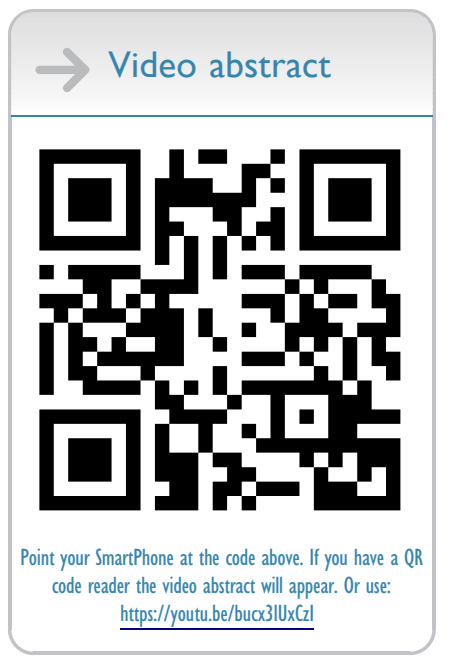

Correspondence: Hyejin Lee Department of Occupational Therapy, Choonhae College of Health Sciences, 9, Daehak-gil, Ungchon-myeon, Ulju-gun, Ulsan, 44965, Republic of Korea

Tel +82-10-8784-6389

Fax +82-52-270-0319

Email dnjstndd16389@hanmil.net
Purpose: In this study, we investigated the effect of visual and cognitive functions of elderly taxi drivers on safe driving behavior. We aimed to identify factors that interfere with safe driving in an aging Korean society in elderly taxi drivers.

Participants and Methods: A total of 203 elderly taxi drivers, aged $>65$, working at 3 companies in a single city were assessed over 4 weeks from December 1 to December 30, 2017, using the Motor-Free Visual Perception Test, Korean Montreal Cognitive Assessment, and Korean Safe Driving Behavior Measure. To examine the effects of cognitive and visual functions on driving behavior, we performed a stepwise multiple linear regression analysis $(\mathrm{p}<0.05)$.

Results: All 4 subdomains of safe driving behaviors were significantly correlated with the cognitive subdomains of attention and abstraction and the visual perception subdomains of visual closure 1 and figure-ground.

Conclusion: More systematic assessments of the relationship between driving behavior and cognitive and visual function in elderly individuals are needed.

Keywords: elderly, safe driving behavior measure, taxi driving, driving, cognitive function

\section{Introduction}

The drivers' cognitive abilities have a significant relationship to safety performance, such as attention, visuospatial skills, executive function, memory and psychomotor skills. ${ }^{1}$ In previous Research has consistently shown that older individuals with cognitive decline and those with cognitive impairment exhibit significantly poorer driving performance than other drivers. ${ }^{2}$

Researchers have underlined the need for clinicians, family members, and people with mild cognitive impairment (MCI) to watch for changes in driving that may become increasingly problematic over time. ${ }^{3}$

The Korean population is rapidly aging, with older adults ( $>65$ years) expected to compose $14.3 \%$ of the population in 2018 and $41.0 \%$ in 2060 , which has led to a need for elderly welfare policies in South Korea. ${ }^{4}$ With the increasing elderly population, there has been a concurrent increase in the number of accidents involving older drivers over the past 5 years: according to Korean Road Traffic Authority data, there were 15,190 cases in $2013,17,590$ in 2014, 20,275 in 2015, 23,063 in 2016, and 24,429 in 2017. Through May 2018, the number of driving accidents involving senior drivers increased by about $5.9 \%$ compared to the corresponding number in 2017.

Among commercial automobile accidents in 2016, those involving taxis accounted for the largest portion, at $44.5 \%$. Around $12.4 \%$ of these taxi accidents 
took place between midnight and 2 AM, 50.4\% were due to a lack of adherence to safe driving responsibilities: failure to secure a safe distance $(13.7 \%)$, disobedience of traffic signals $(12.4 \%)$, and failure to adhere to cross-section passing regulations $(6.3 \%)$. In most cases $(83.1 \%)$, the offender had obtained their taxi license over 15 years prior, while the age of the offender was led by the group aged 51 to 60 years at $43.0 \%$, followed by group aged over 65 years. ${ }^{5}$ Driving autonomy has increased the scope of movement and activity for elderly individuals and plays an important role in maintaining their social networking capabilities and independence. ${ }^{6}$ Lower mobility ultimately lowers the well-being of elderly adults. Additionally, in the case of elderly taxi drivers, their vehicle dependent mobility is closely tied with their economic livelihoods. This link highlights the need for clear standards for driving evaluation and associated legal regulations.

Driving is a complex activity requiring the simultaneous completion of numerous tasks, and always carries the risk of an accident, which is influenced by the cognitive and decision-making abilities of the driver. ${ }^{7}$ Often, elderly individuals give up driving in favor of public transit. However, the use of public transit can be a major hindrance to participating in various hobbies and social activities for elderly individuals. To avoid accidents, drivers must be able to accurately assess their current situation while driving, and to make decisions based on that assessment. More specifically, safe driving can be defined as the accurate operation of the lighting, steering, and other devices of the vehicle, as well as the ability to avoid inflicting harm based on the traffic situation and vehicle structure and performance. ${ }^{8}$ Objective evaluations of the physical abilities of elderly drivers ( $>65$ years) using detailed driving aptitude tests have indicated that their body movements are much slower and more erratic than those of younger individuals, and they are slower to respond in obstacle dodging tests, committing more errors. Accordingly, elderly drivers are more likely to cause accidents or delays. Moreover, in driving simulator tests where the conditions are simulated to closely resemble those during actual driving the average driving speed of elderly drivers was much lower than that of younger drivers. Their reaction times in unexpected situations were also much longer, which led to a decrease in their abilities to respond to dangerous situations arising in a traffic scene. ${ }^{9}$

Studies have reported that the deterioration of visual perception in the normal process of aging is highly correlated with problems in maintaining balance and daily activities in elderly individuals. ${ }^{10}$ Additionally, deterioration of visual perception due to age or neurological problems can lead to difficulties in the cognition of objects and their spatial relationships, as well as problems with independent activities, task completion, and participation in leisure activities and hobbies. ${ }^{11}$ Visual perception has been confirmed to be an important factor for driving. Therefore, it is important to verify the adequacy of the visual perception abilities of elderly individuals for safe driving practices. Occupational therapists, generalists, and driving rehabilitation specialists (DRSs) alike can play a major role in identifying drivers at risk. ${ }^{12-14}$

Occupational therapists need to understand more clearly the nature of driving errors leading to crash-related injuries and adapt their driving evaluation practices accordingly that is, to identify, manage, and prevent such errors. $^{15}$ Occupational therapists, especially those with advanced training, have the knowledge and skills to understand progressive conditions and aging-associated changes that affect driving. Indeed, driving rehabilitation specialists (DRSs) most of whom are occupational therapists have been recognized as the experts best equipped to evaluate older adults' driving ability. ${ }^{16}$

Llamazareset al Research suggests that the results of this study suggest that commuting accidents involving professional drivers differ in demographic and situational issues from general and on-duty professional drivers' traffic crashes. ${ }^{17}$ A number of previous studies have reported that experienced taxi drivers have superior spatial knowledge and wayfinding skills. ${ }^{18}$ The goal of this study was to examine the relationship among safe driving behavior, visual perception, and cognitive ability in a specific group of individuals who were confident in their ability to drive namely, elderly taxi drivers and identify factors interfering with safe driving at an older age. This study can be used as a reference for improving driving practices in elderly individuals.

\section{Participants and Methods}

\section{Participants}

This study was conducted in 203 taxi drivers, including elderly ( $>65$ years) adults, working for companies A, B, and $\mathrm{C}$ in city $\mathrm{P}$ over 4 weeks from December 1 to December 30, 2017. We selected subjects who sufficiently understood the study objective and agreed to participate. To conduct research using surveys and assessment reports, all details of the study procedures were submitted to the Science Research Council of Inje University, which approved the study protocol. According to the 
Declaration of Helsinki guidelines, the Ethics Committee of the affiliated Inje University approved this study, and all patients gave written informed consent.

\section{Research Tools}

\section{Motor-Free Visual Perception Test 3 (MVPT-3)}

The MVPT-3 was used to evaluate the participants' visual perception ability independently of their motor ability. This standardized tool has high reliability and validity. In particular, the interrater reliability of this test ranges from 0.77 to 0.83 with a correlation, $r$, of 0.81 . In addition, it requires less time to complete compared to other tests. ${ }^{19}$ The test is divided into the following 8 sections: visual discrimination, form constancy, visual short-term memory 1, visual closure 1, spatial orientation, figure ground, visual closure 2 , and visual short-term memory 2 . There are a total of 65 items; for children younger than 10, only items 1-40 are used. Individuals over 11 years of age are instructed to answer items 14-65. These 51 items were used in the present study. Higher scores indicated better visual perception ability. ${ }^{20}$ In this study, each score of the MVPT-3 sub-area was individually calculated and statistically analyzed.

\section{Korean Version of the Montreal Cognitive Assessment (MoCA-K)}

The MoCA-K is used to identify patients with mild cognitive impairment. This test comprises 7 subscales, including visuospatial/executive (5 items), vocabulary (3 items), attention ( 8 items), sentence repetition ( 3 items), abstraction (2 items), delayed recall (5 items), and orientation (6 items). The total score of the scale ranges from 0 to 30 , with 1 point automatically given to participants with less than 6 years of total education to account for education-level-related differences in cognition. In this study, MoCA-K divided into 7 sub-areas, each score was calculated by area and statistically analyzed. The MoCA$\mathrm{K}$ takes 10-15 minutes to complete. Much like in the Korean Mini-Mental State Examination (MMSE), correctly answering an item is awarded 1 point. The MoCA-K was developed as a more accurate measure of mild cognitive impairment compared to the MMSE, and uses a cutoff of $\leq 22$ for mild cognitive impairment. The reliability (Cronbach's $\alpha$ ) of the MoCA-K at the time of tool development was $0.83 .{ }^{8}$ The MoCA-K also had good criterion validity, based on an $\mathrm{r}$ value of 0.65 $(\mathrm{P}<0.001)$ with the MMSE and $0.62(\mathrm{P}<0.001)$ with the Clinical Dementia Rating scale. ${ }^{21}$

\section{Korean Safe Driving Behavior Measure (K-SDBM)}

The SDBM can be used as a reliable tool to assess older drivers' safe driving behavior in occupational therapy practice. The K-SDBM is a translated version of the selfreported SDBM scale developed by Classen et $\mathrm{al}^{22}$. It was adapted during translation to suit Korean driving conditions. The translation process included a reverse translation evaluation, which yielded a high reliability coefficient of 0.75 . It comprises a total of 37 items, each scored based on the following answer options: very difficult (4), rather difficult (3), slightly difficult (2), and not difficult (1). In this study, each score is divided into four sub-areas (In a driving situation that requires attention, Fora general driving skill, In an external environment and weather, In terms of space and distance) in Section C of K-SDBM. ${ }^{23}$ It was calculated by area and analyzed statistically.

\section{Data Analysis}

All statistical analyses were conducted using PASW Statistics 23.0 (SPSS Inc., Chicago, IL). We used descriptive statistics to conduct a frequency analysis of the subjects' general characteristics. To examine the effects of cognitive and visual functions on driving behavior, we performed a stepwise multiple linear regression analysis $(\mathrm{p}<0.05)$.

\section{Results}

\section{Participant General Characteristics and Driving Experience}

A total of 203 subjects were included (Table 1). All subjects were male (100\%), 94 were aged 60-64 (46.3\%), and 109 were aged $65-75(53.7 \%)$. The most frequent education level achieved (scored as graduation) was high school (107 subjects, 52.7\%). The most common length of driving experience was $\geq 16$ years (107 subjects, 52.7\%). Employment was permanent for 117 subjects (57.6\%) and non-regular for 86 subjects (42.4\%). A majority (85, $41.9 \%)$ of the subjects worked during daytime, 54 (26.6\%) during nighttime, and 64 (31.5\%) in day-night shifts.

\section{Effects of Cognitive Function on Driving Behavior in Elderly Taxi Drivers}

To investigate the effects of the cognitive subdomains (visuospatial/executive, vocabulary, attention, sentence repetition, abstraction, delayed recall, orientation) on driving behaviors, we performed stepwise multiple linear regressions using cognitive subdomains as the independent variables and the 4 driving behavior subdomains as the 
Table I General Characteristics of the Subjects

\begin{tabular}{|c|c|c|c|}
\hline Item & Category & $N(203)$ & $\begin{array}{l}\text { Percentage } \\
\text { (\%) }\end{array}$ \\
\hline Sex & $\begin{array}{l}M \\
F\end{array}$ & $\begin{array}{l}203 \\
0\end{array}$ & $\begin{array}{l}100 \\
0\end{array}$ \\
\hline Age & $\begin{array}{l}60-64 \\
65-70\end{array}$ & $\begin{array}{l}94 \\
109\end{array}$ & $\begin{array}{l}46.3 \\
53.7\end{array}$ \\
\hline Education & $\begin{array}{l}\text { None } \\
\text { Elementary } \\
\text { Middle } \\
\text { Hige } \\
\text { Junior college or higher }\end{array}$ & $\begin{array}{l}0 \\
20 \\
33 \\
43 \\
107\end{array}$ & $\begin{array}{l}0 \\
10.8 \\
20.7 \\
52.7 \\
15.8\end{array}$ \\
\hline Years driven & $\begin{array}{l}1-5 \\
6-10 \\
11-15 \\
>16\end{array}$ & $\begin{array}{l}20 \\
33 \\
43 \\
107\end{array}$ & $\begin{array}{l}9.9 \\
16.3 \\
21.2 \\
52.7\end{array}$ \\
\hline $\begin{array}{l}\text { Employment } \\
\text { type }\end{array}$ & $\begin{array}{l}\text { Permanent } \\
\text { Non-regular }\end{array}$ & $\begin{array}{l}117 \\
86\end{array}$ & $\begin{array}{l}57.6 \\
42.4\end{array}$ \\
\hline Working time & $\begin{array}{l}\text { Daytime } \\
\text { Night } \\
\text { Weekly and night shifts }\end{array}$ & $\begin{array}{l}85 \\
54 \\
64\end{array}$ & $\begin{array}{l}41.9 \\
26.6 \\
31.5\end{array}$ \\
\hline $\begin{array}{l}\text { Monthly } \\
\text { salary(l) }\end{array}$ & $\begin{array}{l}50-100 \\
100-150 \\
150-200 \\
>200\end{array}$ & $\begin{array}{l}97 \\
84 \\
11 \\
11\end{array}$ & $\begin{array}{l}47.8 \\
41.4 \\
5.4 \\
5.4\end{array}$ \\
\hline $\begin{array}{l}\text { Confidence in } \\
\text { driving }\end{array}$ & $\begin{array}{l}\text { Very confident } \\
\text { Have confidence } \\
\text { Usually } \\
\text { Not confident } \\
\text { Very not confident }\end{array}$ & $\begin{array}{l}189 \\
14 \\
0 \\
0 \\
0\end{array}$ & $\begin{array}{l}93.1 \\
6.89 \\
0 \\
0 \\
0\end{array}$ \\
\hline
\end{tabular}

dependent variables (Table 2). For "situations requiring awareness," the sample regression equation ( $\mathrm{F}=20.856$, $p<0.001)$ was statistically significant, and the explanatory power of the model was $17.3 \%$, with a coefficient of determination value (R2) of 0.173 . Among the cognitive function subdomains, only attention $(\beta=0.334, p<0.001)$ and abstraction $(\beta=0.221, p<0.000)$ showed significant effects on "situations requiring awareness". The sample regression equation $(\mathrm{F}=14.394, p<0.001)$ for "general driving skills" was also statistically significant, with an explanatory power of $17.8 \%$ and $\mathrm{R} 2=0.178$. Among the cognitive function subdomains, only vocabulary $(\beta=$ $-.138, \quad p<0.039)$, attention $(\beta=0.315, \quad p<0.001)$, and abstraction $(\beta=0.261, p<0.001)$ showed significant effects on "general driving skills". For "external environment and weather," the sample regression equation $(\mathrm{F}=16.447$, $p<0.001)$ was statistically significant as well, and the explanatory power was $14.1 \%$, with $\mathrm{R} 2=0.141$. Only attention $(\beta=0.309, \quad p<0.001)$ and abstraction $(\beta=0.190$, $p<0.004)$ showed significant effects on "external environment and weather". For "sense of space and distance," the sample regression equation $(\mathrm{F}=13.596, p<0.001)$ was statistically significant, with an explanatory power of $12.0 \%$ and $\mathrm{R} 2=0.120$. Among the cognitive function subdomains, only attention $(\beta=0.250, \quad p<0.001)$ and abstraction $(\beta=0.219, p<0.001)$ showed significant effects on "sense of space and distance".

\section{Effects of Visual Perception Function on Driving Behavior in Elderly Taxi Drivers}

To investigate the effects of visual perception subdomains on driving behavior, we performed stepwise multiple linear regressions using visual perception subdomains as the independent variables and the 4 driving behavior subdomains as dependent variables (Table 3). For "situations requiring awareness," the sample regression equation ( $\mathrm{F}=20.664, p<0.001)$ was statistically significant, and the explanatory power of the model was $29.5 \%$, with $\mathrm{R} 2=0.295$. Among the visual perception subdomains, only visual closure $1(\beta=0.288, p<0.001)$, figure-ground $(\beta=0.322, p<0.001)$, visual closure $2(\beta=0.177, p<0.019)$, and visual short-term memory $2(\beta=-.129, p<0.047)$ showed significant effects on "situations requiring awareness". For "general driving skills," the regression equation ( $\mathrm{F}=13.352, p<0.001)$ was also statistically significant, with an explanatory power of $11.8 \%$ and $\mathrm{R} 2=0.118$. Visual closure $1 \quad(\beta=0.270, \quad p<0.001)$ and figure-ground $(\beta=0.180, p<0.008)$ showed significant effects on "general driving skills". For "external environment and weather," the sample regression equation $(\mathrm{F}=40.094, p<0.001)$ was statistically significant as well, and the explanatory power was $50.4 \%$, with $\mathrm{R} 2=0.504$. Visual short-term memory 1 $(\beta=-.218, p<0.001)$, visual closure $1 \quad(\beta=0.359, p<0.001)$, spatial orientation $(\beta=0.277, p<0.001)$, and visual closure $2(\beta=0.266, p<0.001)$ all showed significant effects on "external environment and weather". For "sense of space and distance," the sample regression equation ( $\mathrm{F}=13.570$, $p<0.001)$ was also statistically significant, with an explanatory power of $11.9 \%$ and $\mathrm{R} 2=0.119$. Among the visual perception subdomains, only visual closure $1 \quad(\beta=0.241$, $p<0.001)$ and figure-ground $(\beta=0.218, p<0.001)$ showed significant effects on "sense of space and distance". 
Table 2 Effects of Cognitive Function on Driving Behavior in Elderly Taxi Drivers

\begin{tabular}{|c|c|c|c|c|c|c|}
\hline Dependent Variables & Independent Variables & B & SE & $\beta$ & $\mathbf{t}$ & $\mathbf{R}^{2}$ \\
\hline \multirow[t]{3}{*}{ In a driving situation that requires attention } & (Constant) & 32.287 & 2.336 & & $13.822 * * *$ & $\mathrm{~F}=20.856 * * *$ \\
\hline & Attention & 2.113 & 0.409 & 0.334 & $5.173^{* * *}$ & $R=0.173$ \\
\hline & Abstraction & 3.023 & 0.884 & 0.221 & $3.419 * * *$ & $R^{2} .164$ \\
\hline \multirow[t]{4}{*}{ Fora general driving skill } & (Constant) & 32.793 & 2.101 & & $15.608 * * *$ & $\mathrm{~F}=14.394 * * *$ \\
\hline & Vocabulary & $-1.46 \mid$ & 0.703 & -.138 & $-2.078^{*}$ & $R=0.178$ \\
\hline & Attention & 0.699 & 0.143 & 0.315 & $4.880 * * *$ & $R^{2} .166$ \\
\hline & Abstraction & 1.253 & 0.319 & $0.26 \mathrm{I}$ & $3.927 * * *$ & \\
\hline \multirow[t]{3}{*}{ In an external environment and weather } & (Constant) & 10.856 & 1.782 & & $6.093 * * *$ & $\mathrm{~F}=16.447^{* * *}$ \\
\hline & Attention & 1.464 & 0.312 & 0.309 & $4.698 * * *$ & $\mathrm{R}=0.14 \mathrm{I}$ \\
\hline & Abstraction & 1.944 & 0.674 & 0.190 & $2.884 * *$ & $\mathrm{R}^{2} .133$ \\
\hline \multirow[t]{3}{*}{ In terms of space and distance } & (Constant) & 22.110 & 0.791 & & $27.935 * * *$ & $\mathrm{~F}=13.596 * * *$ \\
\hline & Attention & 0.52 & 0.138 & 0.250 & $3.754 * * *$ & $R=0.120$ \\
\hline & Abstraction & 0.986 & 0.300 & 0.219 & $3.292 * *$ & $R^{2} .111$ \\
\hline
\end{tabular}

Notes: $\mathrm{p}^{*<0} .1, \mathrm{p}^{* *}<0.05, \mathrm{p}^{* * *}<0.01$

Table 3 Effects of Visual Perception Function on Driving Behavior in Elderly Taxi Drivers

\begin{tabular}{|c|c|c|c|c|c|c|}
\hline Dependent Variables & Independent Variables & B & SE & $\boldsymbol{\beta}$ & $\mathbf{t}$ & $\mathbf{R}^{2}$ \\
\hline \multirow[t]{5}{*}{ In a driving situation that requires attention } & (Constant) & 39.245 & 1.650 & & $23.787 * * *$ & $\mathrm{~F}=20.664 * * *$ \\
\hline & Visual Closure I & 0.789 & 0.201 & 0.288 & $3.930 * * *$ & $R=0.295$ \\
\hline & Figure Ground & 1.899 & 0.377 & 0.322 & $5.039 * * *$ & $\mathrm{R}^{2} .280$ \\
\hline & Visual Closure 2 & 1.067 & 0.451 & 0.177 & $2.366 * *$ & \\
\hline & Visual short-term Memory 2 & -.743 & 0.371 & -.129 & $-1.999 * *$ & \\
\hline \multirow[t]{3}{*}{ Fora general driving skill } & (Constant) & 31.451 & 0.508 & & $61.896 * * *$ & $\mathrm{~F}=13.352^{* * *}$ \\
\hline & Visual Closure I & 0.259 & 0.064 & 0.270 & $4.035 * * *$ & $R=0.118$ \\
\hline & Figure Ground & 0.371 & 0.138 & 0.180 & $2.608 * *$ & $R^{2} .109$ \\
\hline \multirow[t]{5}{*}{ In an external environment and weather } & (Constant) & 13.278 & 1.498 & & $8.864 * * *$ & $\mathrm{~F}=40.094^{* * *}$ \\
\hline & Visual short-term Memory I & -.872 & 0.239 & -.218 & $-3.649 * * *$ & $R=0.504$ \\
\hline & Visual Closure I & 0.735 & 0.138 & 0.359 & $5.331 * * *$ & $R^{2} .492$ \\
\hline & Spatial Orientation & 0.734 & 0.187 & 0.277 & $3.923 * * *$ & \\
\hline & Visual Short-term Memory 2 & 1.202 & 0.305 & 0.266 & $3.946 * * *$ & \\
\hline \multirow[t]{3}{*}{ In terms of space and distance } & (Constant) & 24.064 & 0.476 & & $50.595 * * *$ & $\mathrm{~F}=13.570^{* * *}$ \\
\hline & Visual Closure I & 0.217 & 0.060 & $0.24 I$ & $3.606 * * *$ & $R=0.119$ \\
\hline & Figure Ground & 0.423 & 0.130 & 0.218 & 3.262 & $R^{2} .111$ \\
\hline
\end{tabular}

Notes: $\mathrm{p}^{* *}<0.05, \mathrm{p}^{* * * * 0.01}$

\section{Discussion}

In the present study, we investigated the relationship between driving behavior and visual perception and cognitive function of elderly taxi drivers, and found the effect of visual perception and cognitive function on safe driving behavior. Visual perception and cognitive abilities can have a profound effect on seniors' ability to drive. Deterioration of function due to aging increases the risk of accidents in the elderly, and the record of serious injuries increases when an accident occurs. Therefore, the process of preventing accidents and recognizing various state changes that affect safe driving performance by the elderly has important implications at the individual and social level. ${ }^{24,25}$

Among the many factors increasing the risk of a road accident are the characteristics of older age; ie, to drive safely, drivers require a minimal level of visual and auditory ability, along with intact perceptual, cognitive, and executive functions. ${ }^{26}$ When we examined the effects of 
cognitive subdomains on driving behavior, we found significant relations of attention and abstraction with all 4 driving behavior subdomains. This result demonstrates that, among cognitive functions, attention and abstraction have especially large effects on driving in the elderly population. In future research, it will be necessary to carefully examine the roles of attention and abstraction in driving rehabilitation and assessment of elderly individuals. In the process of aging, perception, motor, and cognitive functions gradually deteriorate, which is a factor in continuing driving. ${ }^{27}$ Research has shown that the cognitive domains of executive function, attention, visuospatial skills, memory, and overall mental status are associated with the crash risk of older drivers who are experiencing age-related cognitive changes. ${ }^{28}$ In a study that studied road driving behavior in older drivers with mild cognitive impairment, MCI safe drivers had higher levels of attention, memory, and speech impairment, and MCI unsafe drivers had higher levels of space-time, executive function, and attention impairment. ${ }^{29}$

Driving simulator studies of older drivers have found that MMSE is highly predictive of driver safety. ${ }^{30}$ In this study, the MoCA-K evaluation tool was used for cognitive function, and the MoCA-K evaluation tool is an evaluation tool similar to MMSE, which measures mild cognitive impairment. As demonstrated in previous studies, MoCA-K is thought to be an appropriate tool for evaluating cognitive function related to driving performance of the elderly.

When we examined the effects of the visual perception subdomains on driving behavior, we observed significant relations of visual closure 1 and figure-ground with all 4 driving behavior subdomains. Therefore, among the aspects of visual perception, visual closure and figureground have especially large effects on driving in the elderly population. Future studies will need to examine visual closure and figure-ground in more detail in the context of driving rehabilitation and assessment for elderly individuals.

In studying the relationship between driving confidence and driving behavior in drivers of different ages, Lee et $\mathrm{al}^{31}$ reported that older drivers generally had more than 10 years of experience and therefore were likely to be confident in their driving abilities. Nevertheless, similar to our results, they found that aging adults experienced difficulty in driving conditions such as rain, snow, or heavy traffic, and sought to avoid these situations. Based on these findings, we predict that these weather and external environment factors will also be found to cause difficulties for professional drivers, and even more so for elderly drivers in general. Because reduced performance in visual closure and figure-ground can complicate driving in conditions of poor visibility, such as in rain or snow, it is important to reduce the risk of accidents by avoiding driving when the weather or external environment cause difficulties. Previous studies that reported the driving behavior characteristics of elderly drivers also reported that elderly drivers tend to avoid driving at night or in rain. ${ }^{32,33}$ Visual perception impairment due to elderly or damage to the central nervous system can cause problems with several behaviors (eg, standing straight and moving objects) as well as spatial cognition. ${ }^{34}$ Combining the results of the previous study and the results of this study, the elderly driver can conclude that he or she has the characteristics of being aware of an increase in operational risk when driving is difficult in certain driving conditions, such as at night or in bad weather. Therefore, it is important to use visual perception tests, particularly those including figure-ground assessment, when evaluating driving ability in the elderly population.

To ensure traffic safety, clear solutions and regulations for elderly taxi drivers are required. Because elderly taxi drivers cannot abruptly cease driving without it having a significant effect on their livelihoods, in addition to other negative outcomes such as decreased quality of life, such solutions and regulations need to be developed without much delay. Methods to consider include the validation of various driving assessments, particularly those of driving behavior predictors, and restricting driving among older taxi drivers who have a high risk of accidents. Moreover, there is a need for more studies, analyzing a more diverse range of variables such as response speed and physical ability, along with visual perception and cognitive ability, in older individuals.

\section{Limitation}

The limitations of this study are as follows: first, the participants were limited to workers in the taxi transportation industry; therefore, the results cannot apply to all older drivers.

\section{Conclusion}

In the future, it will be important to conduct more systematic driving assessments, including in the areas of cognitive function and visual perception, in elderly individuals, and to continue research into institutional protection and appropriate interventions for elderly drivers. 


\section{Funding}

This work was supported by the 2017 Inje University research grant.

\section{Disclosure}

The authors report no conflicts of interest in this work.

\section{References}

1. Guo M, Hu L, Ye L. Cognition and driving safety: how does the highspeed railway drivers' cognitive ability affect safety performance? Transp Res Part F Traffic Psychol Behav. 2019;65:10-22. doi:10. 1016/j.trf.2019.07.006

2. Zicat E, Bennett JM, Chekaluk E, Batchelor J. Cognitive function and young drivers: the relationship between driving, attitudes, personality and cognition. Transp Res Part F Traffic Psychol Behav. 2018;55:341-352. doi:10.1016/j.trf.2018.03.013

3. Wadley VG, Okonkwo O, Crowe M, et al. Mild cognitive impairment and everyday function: an investigation of driving performance. $J$ Geriatr Psychiatry Neurol. 2009;22(2):87-94. doi:10.1177/089198 8708328215

4. Statistics Korea [homepage on the Internet]. Seoul: 2017 statistics of the elderly; 2017. Available from: http://kostat.go.kr/portal/korea/ index.action. Accessed May 1, 2017.

5. Road Traffic Authority [homepage on the Internet]. Seoul: operation status for the elderly; 2017. Available from: http://www.koroad.or.kr/. Accessed May 1, 2017.

6. Persson D. The elderly driver: deciding when to stop. Gerontologist. 1993;33(1):88-91. doi:10.1093/geront/33.1.88

7. Johansson K, Lundberg C. The 1994 international consensus conference on dementia and driving: a brief report. Alzheimer Dis Assoc Disord. 1997;11(1):62-69. doi:10.1097/00002093-199706001-00013

8. Korean Transportation Safety Authority [homepage on the Internet]. Seoul: traffic accidents causes and traffic safety countermeasures for the elderly considering traffic accidents causes; 2011. Available from: http://www.kotsa.or.kr/. Accessed May 1, 2011.

9. Road Traffic Authority [homepage on the Internet]. Road traffic authority briefing. Transportation policy; 2014. Available from: http://www.koroad.or.kr/. Accessed May 1, 2014.

10. Jang MY, Lee YJ. The relationship between balance ability and visual perception ability in health elderly. J Korean Occup Ther. 1999;7 (1):68-74.

11. Yang YA. Occupational Therapy with Elders. Seoul: Gyechuk publishing house; 2016:165.

12. Bethesda MD. Driving evaluation and retraining programs: a report of good practices. Am J Occup Ther. 2004a.

13. Bethesda MD. Report on community mobility/driver safety intervention as an area for specialty certification. Am J Occup Ther. 2004b.

14. American Occupational Therapy Association. Driving and community mobility. Am J Occup Ther. 2005;59:666-670. doi:10.5014/ ajot.59.6.666

15. Classen S, Shechtman O, Awadzi KD, Joo Y, Lanford DL. Traffic violations versus driving errors of older adults: informing clinical practice. Am J Occup Ther. 2010;64:233-241. doi:10.5014/ajot.64.2. 233

16. Jones J, Dickerson A, Flaten HK, Belmashkan S, Betz ME. Driving rehabilitation specialists' perspectives on older driver evaluations. Am J Occup Ther. 2016;70(2):7002270010p1. doi:10.5014/ajot.2016. 016915
17. Llamazares J, Useche SA, Montoro L, Alonso F. Commuting accidents of Spanish professional drivers: when occupational risk exceeds the workplace. Int J Occup Saf Ergon. 2019;1-9. doi:10.1080/ 10803548.2019.1619993

18. Wakabayashi Y, Itoh S, Nagami Y. The use of geospatial information and spatial cognition of taxi drivers in Tokyo. Procedia Soc Behav Sci. 2011;21:353-361. doi:10.1016/j.sbspro.2011.07.030

19. Colarusso RP, Hammill DD. Motor-Free Visual Perception TestRevised Manual. California: Academic therapy publications; 1996.

20. Cate Y, Richards L. Relationship between performance on tests of basic visual functions and visual-perceptual processing in persons after brain injury. Am J Occup Ther. 2000;54(3):326-334. doi:10.50 14/ajot.54.3.326

21. Nasreddine ZS, Phillips NA, Bedirian V, Charbonneau S, Whitehead V, Collin I. The Montreal Cognitive Assessment, MoCA: a brief screening tool for mild cognitive impairment. J Am Geriatr Soc. 2005;53(4):695-699. doi:10.1111/j.1532-5415.2005.53221.x

22. Classen S, Wen PS, Velozo CA, et al. Rater reliability and rater effects of the safe driving behavior measure. Am J Occup Ther. 2012;66(1):69-77. doi:10.5014/ajot.2012.002261

23. Jeong YJ, Jeong MY, Yu EY, Park JH, Sherrilene C, Sandra MW. Development and reliability of Korean Safe Driving Behavior Measure (K-SDBM). J Korean Occup Ther. 2014;22(3):57-68. doi:10.14519/jksot.2014.22.3.05

24. Baldock MRJ, McLean J. Older Drivers: Crash Involvement Rates and Causes. Adelaide, South Australia: Centre for Automotive Safety Research; 2005.

25. Meng A, Siren A. Cognitive testing of older drivers does not produce safety benefits. Accident Anal Prev. 2012;45(2):634-638. doi:10.10 16/j.aap.2011.09.032

26. Lee HJ, Gu YH. Study on Korean Self-Report Safe Driving Behavior Measure (K-SDBM) by drivers aged 65 or over in the taxi service industry. J Korean Aging Indust. 2015;7(1):17-28.

27. Anstey KL, Windsor TD, Luszcz MA, Andrews GR. Predicting driving cessation over 5 years in older adults: psychological wellbeing and cognitive competence are stronger predictors than physical health. J Am Geriatr Soc. 2006;54(1):121-126. doi:10.1111/j.15325415.2005.00471.x

28. Anstey K, Wood J, Lord S, Walker J. Cognitive, sensory and physical factors enabling driving safety in older adults. Clin Psychol Rev. 2005;25:45-65. doi:10.1016/j.cpr.2004.07.008

29. Eramudugolla R, Huque MH, Wood J, Anstey KJ. On-road behavior in older drivers with mild cognitive impairment. $J$ Am Med Dir Assoc. 2020;19:1-7.

30. Mathias J, Lucas L. Cognitive predictors of unsafe driving in older drivers: a meta-analysis. Int Psychogeriatr. 2009;21:637-653. doi:10.1017/S1041610209009119

31. Lee SC, Oh JS, Park SJ, Lee SY, Kim IS. The relationship between driving confidence and driving behaviour in elderly and young drivers. Kor Psych Assoc Culture. 2006;12(1):81-102.

32. Rimmöo PA, Hakamies-Blomqvist L. Older drivers' aberrant driving behaviour, impaired activity, and health as reasons for self-imposed driving limitations. Transp Res Part F Traffic Psychol Behav. 2002;5 (1):47-62. doi:10.1016/S1369-8478(02)00005-0

33. Molnar LJ, Eby DW, Charlton JL, et al. Driving avoidance by older adults: is it always self-regulation? Accident Anal Prev. 2013;57:96104. doi:10.1016/j.aap.2013.04.010

34. Ranvensberg CD, Tyldesley DA, Rozendal RH, Whiting HT. Visual perception in hemiplegic patients. Arch Phys Med Rehabil. 1984;65 (6):304-309. 


\section{Publish your work in this journal}

Risk Management and Healthcare Policy is an international, peerreviewed, open access journal focusing on all aspects of public health, policy, and preventative measures to promote good health and improve morbidity and mortality in the population. The journal welcomes submitted papers covering original research, basic science, clinical \& epidemiological studies, reviews and evaluations, guidelines, expert opinion and commentary, case reports and extended reports. The manuscript management system is completely online and includes a very quick and fair peer-review system, which is all easy to use. Visit http://www.dovepress.com/testimonials.php to read real quotes from published authors. 